\title{
A COR DO INFINITO E A BELEZA INATINGÍVEL: sobre a função simbólica do azul em embalagens de alimentos
}

\author{
Dra. Carla Patrícia de Araújo Pereira \\ Universidade Federal de Campina Grande \\ carla@ddi.ufcg.edu.br
}

Resumo: Este artigo analisa a função simbólica da cor azul no design de embalagens de alimentos, a partir de um conjunto de 612 embalagens comercializadas em supermercados. Foi observado que, sem corresponder à cor dos alimentos em nenhuma embalagem da amostra, o azul foi a segunda cor mais recorrente nos designs. Seu papel mais frequente nas embalagens foi o de indicar características nutricionais específicas vinculadas ao conceito de alimentação saudável, simbolizando a ideia de moderação, temperança e racionalidade. $O$ estudo mostra que a formação do significado baseia-se na relação de oposição que se estabelece entre o azul e as cores quentes características do universo dos alimentos. Concluise que essa mudança do padrão cromático identificada pela pesquisa reflete a ascendência do discurso científico vinculado à alimentação, contexto em que o azul das embalagens representa conceitos de saúde e beleza promovidos pela sociedade nos dias de hoje, integrando um processo mais amplo de propagação de valores e símbolos.

Palavras-chave: semiótica, embalagens de alimentos, cor (simbolismo).

Abstract: This paper analyzes the symbolic function of blue color in food packaging design, starting from a group of 612 packages commercialized in supermarkets. It was observed that, without match the color of the food in any sample packing, the blue was the second most recurring color in designs. His most frequent role in packaging was to indicate specific nutritional characteristics linked to the concept of healthy eating, symbolizing the idea of moderation, self-control and rationality. The study shows that the formation of the meaning is based on the relationship of opposition between the blue and the warm colors features of the universe of food. It is concluded that this change of chromatic pattern identified in the survey reflects the ascendancy of the scientific discourse tied to feeding, context in which the blue packaging represents health and beauty concepts promoted by the society these days, as part of a wider process of spreading values and symbols.

Keywords: semiotics, food packaging, color (symbolism). 


\section{INTRODUÇÃO}

Os usos que fazemos das cores, bem como os significados que atribuímos a elas guardam sua relação com a história, perpetuaram-se através dos usos e costumes, do vestuário, da religião, da arte, da mídia, dos objetos, das teorias da cor, enfim, da cultura como um todo. Embora sejam frequentemente associadas a modismos, as cores têm significados duradouros que as tornam códigos fortes da linguagem visual. Parte de sua eficiência comunicativa reside nesse fato, na possibilidade de existência de um repertório compartilhado, de convenções aprendidas e ensinadas. $E$, embora possa parecer contraditório, a outra parte parece residir exatamente na flexibilidade dos sistemas de significação da cor, em sua capacidade de adaptação aos novos contextos, às novas necessidades e usos.

O sistema de signos da cor no design de embalagens contemporâneo é complexo. A segmentação cada vez maior do mercado tem gerado uma variedade crescente de produtos e de designs, onde os códigos de identificação tradicionais já não parecem ser suficientes. As linguagens se multiplicam e se sobrepõem às categorias de produtos, e, com elas, proliferam-se novos códigos de cores, num contínuo processo de construção da linguagem visual, forçado pela rápida obsolescência dos designs. Observações preliminares desta pesquisa apontaram uma tendência para a ênfase no papel simbólico da cor na comunicação da embalagem de alimentos, em detrimento de funções visuais e indicativas.

Considerando que o design de embalagens é também a representação visual de um conteúdo inserido no discurso publicitário de promoção de marcas e produtos, é, portanto, participante de um processo mais amplo de propagação de valores e símbolos. Por sua produção em larga escala, por sua penetração em diferentes camadas sociais nos diversos países e regiões, e por serem veículos de mensagens, embalagens podem ser consideradas meios de comunicação de massa. Funcionam como mídia, são expostas em outras mídias, e a informação que elas difundem tende a ser incorporada ao repertório visual coletivo. Como parte de estratégias globais de comunicação, somam-se às demais mídias na difusão de modelos e estereótipos e na influência que exercem sobre os modos de vida (cf. CATHELAT, 1968).

\subsection{Objetivos}

Este trabalho investigou a linguagem cromática veiculada pelo design de embalagens contemporâneo, observando embalagens de alimentos comercializados no Brasil. Sem apresentar relação de semelhança com o aspecto cromático dos alimentos em nenhuma embalagem da amostra, o matiz azul foi recorrente no design das embalagens, sendo a segunda cor mais empregada de um total de dez cores examinadas. Seu papel mais frequente foi o de representar a restrição ou redução de nutrientes do alimento, vinculando esse matiz ao conceito de alimentação saudável. Este artigo discute as razões dessa recorrência e analisa a formação do significado simbólico do azul nesse contexto específico.

\section{MÉTODO E REFERENCIAL TEÓRICO}

As ferramentas conceituais de análise utilizadas provêm da semiologia/ semiótica. Investigou-se a linguagem das cores como um sistema de signos, cuja estrutura é formada pelas relações de identidade, de associação, de diferenciação e oposição entre seus elementos, apoiando-se na teoria de Saussure (2006), e 
recorrendo-se a modelos de classificação e análise propostos por Peirce (1995) e pelo Groupe $\mu$ (1993).

O corpus de análise foi composto por 612 embalagens de produtos alimentícios expostos em supermercados da cidade de São Paulo, SP. Os exemplares foram selecionados em função de suas cores predominantes, abrangendo várias categorias de produtos e diversos fabricantes e marcas. Foram definidas dez cores a serem investigadas, identificadas pelos termos básicos de cor: azul, vermelho, amarelo, verde, laranja, violeta, rosa, marrom, preto e branco. Foram selecionadas e catalogadas embalagens nas quais estas dez cores fossem empregadas como cor predominante (aquela de maior área ou maior destaque) ou como segunda cor (segunda maior área ou segundo maior destaque) no design do painel principal.

A análise do material ocorreu em dois níveis. Num primeiro momento, foram identificados os significados primários - os sentidos das cores mais claramente explicitados pelos designs, aqueles que cumprem uma função mais direta na comunicação. Nesta etapa, foram contabilizados os sentidos encontrados para cada uma das dez cores investigadas. Numa fase posterior, a partir dos sentidos primários mais recorrentes, foram examinados graus mais subjetivos da significação.

\section{RESULTADOS DO GRUPO AZUL}

Foram catalogadas no conjunto "azul" as embalagens cuja cor predominante ou segunda cor do painel principal foi visualmente identificada e nomeada como tal, podendo ser tanto um azul tendente ao verde ou ao violeta, desde que claramente diferenciado destes matizes, independente de seu grau de saturação ou claridade. Atendendo a estas condições, durante o período de observação da pesquisa, foram identificadas e registradas 130 embalagens. A cor azul foi uma das cores principais do design em $21,2 \%$ das embalagens do corpus de análise, o que a posiciona como a segunda mais frequente.

Embora em nenhum dos designs observados ela tenha correspondido à cor do conteúdo embalado, em quase $2 / 3$ das embalagens do grupo azul esse matiz foi utilizado para informar algo a respeito do alimento. Como pode ser observado na Tabela 1, o azul frequentemente indicou propriedades objetivas dos produtos alimentícios (em 27,7\% das embalagens desse grupo), remeteu a sabores e variedades $(20,0 \%)$, e identificou categorias (12,3\%). Em pequena proporção, essa cor foi indicativa de modos de processamento e de consumo, e ainda da origem do produto. Em aproximadamente 1/3 das embalagens em que predominou, o azul remeteu à marca e, em apenas em alguns casos, referiu-se diretamente ao comprador/utilizador.

Este matiz assumiu uma grande variedade de significados no design das embalagens examinadas. Entre os sentidos primários identificados, os mais recorrentes foram aqueles relacionados à restrição ou redução de nutrientes, a associação do azul com laticínios, e o conceito de excelência vinculado a determinadas marcas. Conforme pode ser verificado na Tabela 1 (ocorrências C), em 12,3\% das embalagens do conjunto azul, essa cor representou excelência e qualidade superior, seja identificando produtos "premium" e linhas de produtos "especiais", seja como cor características de marcas associadas a estes conceitos. Em 17,7\% (Tabela 1, ocorrências $B$ ), o azul remeteu a laticínios e produtos lácteos, preservando seu papel tradicional de cor característica dessa categoria de produtos (junto com o branco), assim como de marcas de indústrias de laticínios, apesar da grande variedade de 
produtos disponibilizados atualmente. Por fim, em $27,7 \%$ desse conjunto, o azul caracterizou embalagens de produtos identificados como "light", "semidesnatado", "zero", "descafeinado", "desnatado" ou "água e sal", diferenciando-os de suas versões originais e, desse modo, representando a redução ou restrição de nutrientes do alimento (Tabela 1, ocorrências $A$ ).

Tabela 1 - Significados primários e aspectos representados pelo azul no design de embalagens de alimentos.

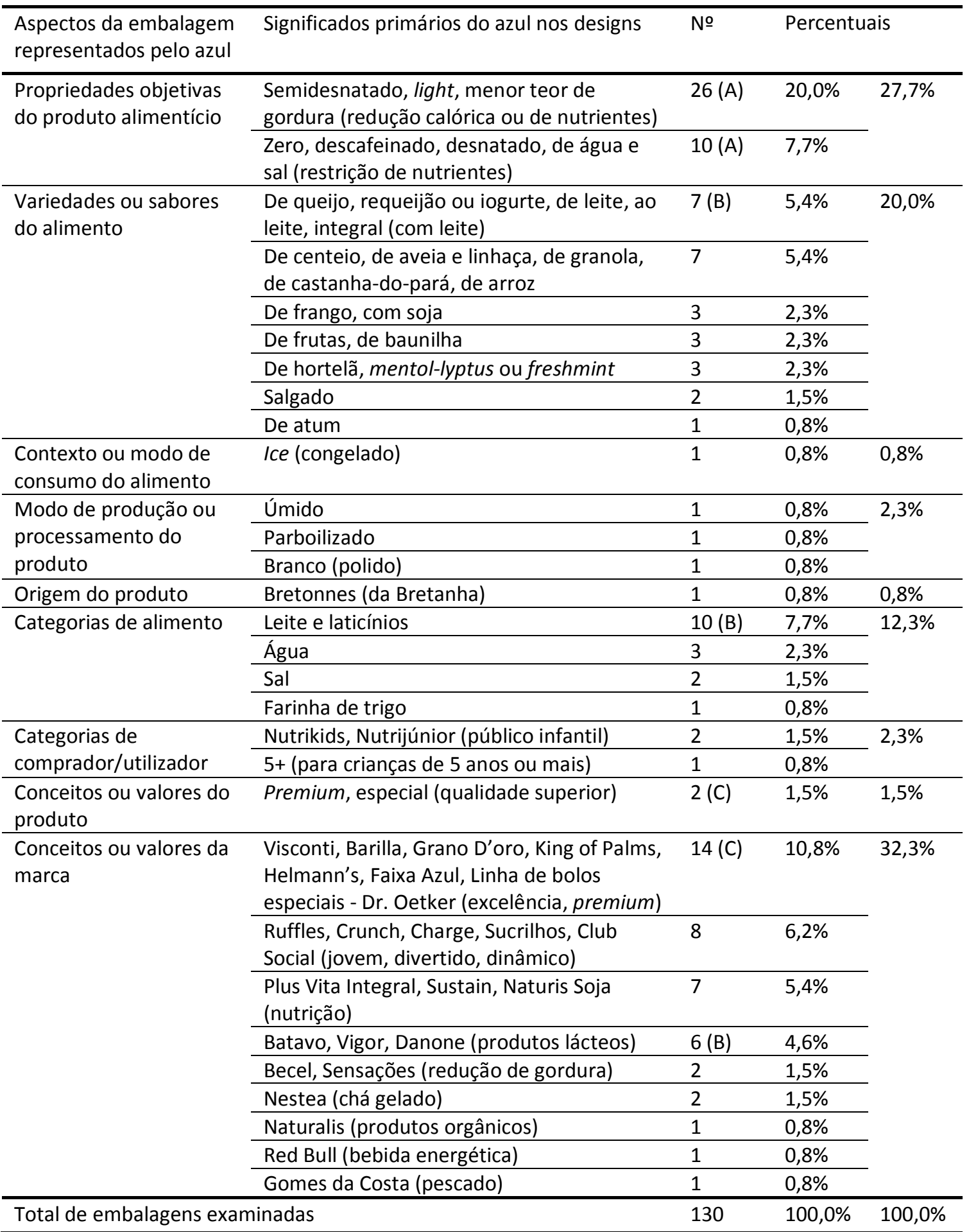

(Fonte: Elaborado pela autora, com base na pesquisa realizada) 


\section{DISCUSSÃO}

A pesquisa constatou que o matiz azul é recorrente no design de embalagens de alimentos. Foi a segunda cor mais presente nos designs, sem ter relação de semelhança com a cor dos alimentos em nenhuma embalagem da amostra. Seu sentido primário mais frequente foi o de restrição ou redução de nutrientes do alimento, observado na caracterização de embalagens de produtos identificados como "light", "zero", "descafeinados" e "desnatados", entre outros.

Estes produtos alimentícios apresentam modificações em sua composição, sendo caracterizados por redução calórica ou isenção ou redução de nutrientes como açúcares, gorduras, sódio e cafeína, e são, por esta razão, considerados mais saudáveis do que os alimentos industrializados convencionais. Em diversos exemplos, observouse que, além da informação verbal obrigatória inserida na rotulagem, estes produtos "mais saudáveis" são diferenciados de suas versões convencionais quase que exclusivamente pela cor da embalagem. No sistema visual da embalagem, esta substituição da cor típica do produto original por cores incomuns àquela categoria indica se tratar de um alimento diferenciado, a cor da embalagem funcionando como índice.

No corpus, além de repetidamente sinalizar a redução de nutrientes, nos casos em que funcionou como indicador de variedades dos produtos o azul também foi uma das cores principais em embalagens de alimentos ricos em fibras e de produtos vitaminados, além de caracterizar embalagens cujas marcas estão vinculadas aos conceitos de nutrição ou alimentação saudável (Figura 1).

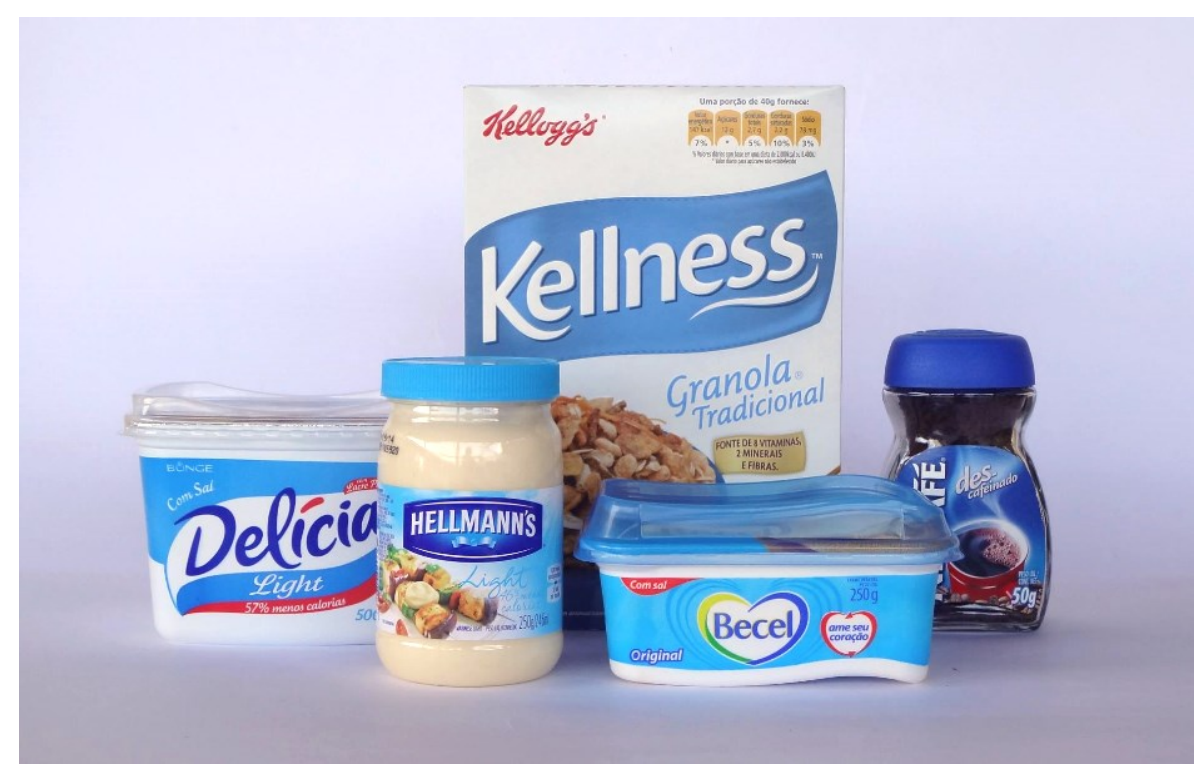

Figura 1 - A cor azul caracterizando embalagens de produtos industrializados associados à ideia de alimentação saudável (Fotografia: Carla Pereira).

Desse modo, embora seus significados primários tenham sido muito diversos, num percentual importante das embalagens do grupo azul (superior a 40\%) esta cor representou um alimento que de algum modo é considerado saudável ou ao menos cuja imagem é construída nesse sentido. No âmbito das fontes consultadas, não consta se tratar de um significado tradicional do azul (cf. PASTOUREAU, 1993; 2000; HELLER, 2004). Num primeiro momento pode-se inferir que o azul assume o sentido de "alimento saudável" pelo contexto em que está inserido, por representar com alguma 
frequência no sistema de signos da embalagem uma opção de alimento menos gorduroso, menos salgado, menos açucarado, e assim por diante.

Ainda que estes significados primários do azul - light, descafeinado, etc. sejam específicos do sistema da embalagem de alimentos, eles se mostram importantes para a compreensão da formação do significado das cores no design. A princípio, porque foram recorrentes no packaging (o que aponta para a formação de um padrão), mas, principalmente, porque se vinculam a uma ideia geral - nutrição e saúde - que remete a sistemas de significação mais amplos, aos significados socioculturais dos hábitos e práticas alimentares, o que permite demonstrar como o sentido da cor na embalagem vai além da informação imediata.

De acordo com a teoria saussuriana, o significado não está apenas no signo considerado isoladamente, mas nas relações que estabelece com os demais signos do mesmo sistema; a linguagem funciona mediante um processo de combinação e substituição dos seus elementos, em que o que se quer dizer se relaciona também com o que não se quer dizer: "[...] um signo só se define como tal no seio de um conjunto de outros signos. Ele tira seu valor, seu rendimento, das oposições que contrai com eles" (SAUSSURE apud DUBOIS et al., 2004 p. 380).

Desse modo, a formação do signo azul=light — ou, numa acepção mais ampla, azul=saudável - pode ser explicada por meio das relações sintagmáticas (referentes às combinações cromáticas) e paradigmáticas (referentes aos campos associativos) desse matiz no âmbito do sistema cromático. No que diz respeito às combinações, pela observação realizada nos designs, estas não parecem ser os principais determinantes na formação deste sentido, já que o azul "saudável" aparece com alguma frequência combinado ao branco, mas também a outras cores.

O significado do azul nesse contexto é extraído principalmente da relação de oposição que se estabelece entre essa cor e as cores quentes características do universo dos alimentos. A presença de uma cor como elemento significativo no design não é interpretada isoladamente, mas em função de um jogo de oposições perceptual e culturalmente estabelecidas entre essa cor e outras cores integrantes do sistema. Nas teorias da cor, azul é frequentemente considerado como oposto ao amarelo e em diferentes contextos da cultura ele também é utilizado como contrário do vermelho. As oposições cromáticas amarelo/azul e vermelho/azul equivalem em diversas situações aos conceitos opostos quente/frio, próximo/distante, material/imaterial, terrestre/celeste, festivo/moral, entre ouros exemplos (GOETHE, 1993; KANDINSKY, 2000; PASTOUREAU, 2000).

Amarelos, laranjas, vermelhos e demais cores quentes caracterizam uma grande variedade de alimentos, como queijos, óleos, massas, molhos, carnes e frutas; e são consideradas cores estimulantes do apetite (BIRREN, 1950; FAVRE et al., 1979; DANGER, 1973; PASTOUREAU, 1993). Elas representam o alimento saboroso, o prazer da alimentação, e, como contraponto ao apelo ao apetite, ao impulso, ao prazer dos sentidos, o design recorre ao azul, cor da razão, da reflexão (cf. HELLER, 2004) e, nesse contexto, cor da moderação, valor que no nível simbólico corresponde ao princípio de restrição de nutrientes representado pelo azul das embalagens.

\subsection{Outros níveis de significação}

No âmbito do packaging de produtos alimentícios, o azul "light" representa a escolha racional do alimento, escolha que não depende dos sabores e aromas 
sugeridos pelos vermelhos, laranjas, amarelos e marrons quentes, escolha que é orientada pelo discurso científico da nutrição e que vai ao encontro dos padrões atuais de saúde e beleza.

Ao mesmo tempo em que se assiste ao crescimento da obesidade no mundo, a sociedade ocidental contemporânea se impõe um ideal de beleza baseado na magreza do corpo, especialmente o corpo feminino. A relação estabelecida pela ciência entre obesidade e doenças cardiovasculares, hipertensão e diabetes elevou a questão a outro patamar, de modo que ser magro tornou-se sinônimo tanto de ser bonito quanto de ser saudável. Nesta ideologia do corpo perfeito (leia-se, magro) se insere o consumo crescente de alimentos leves não apenas por indivíduos obesos, mas por uma parcela cada vez maior da população que passa a incorporar o regime alimentar ao seu dia-a-dia. Na representação visual desses novos hábitos alimentares se veem os estimulantes amarelos, vermelhos e laranjas das embalagens em muitos casos serem substituídos por matizes menos apetitosos como o azul.

Essa mudança para o azul remete ainda a questões mais subjetivas envolvidas na ideologia do corpo magro, mais especificamente, à relação que existe entre alimentação e moralidade. Não se trata de um vínculo recente, entre outras coisas, a gula já foi considerada em algum momento da história um dos sete pecados capitais. Mas o peso moral que está associado à alimentação nos dias de hoje não diz respeito apenas à quantidade do que se come, mas àquilo que se escolhe comer. Em um mundo em que o corpo esguio tornou-se sinônimo de beleza e saúde, um alimento saboroso, mas altamente calórico é considerado uma "tentação", um "pecado", enquanto as opções de alimentos, por assim dizer, mais magros, representam uma alimentação sem "culpa".

O azul é historicamente associado à moralidade, na medida em que se opõe ao vermelho e outras cores vivas, em determinados contextos consideradas festivas ou transgressoras (PASTOUREAU, 2000). Pode-se inferir que o design se apropria dessa antiga associação, e o uso frequente do azul nas embalagens de alimentos leves apoia a ideia de que, se o vermelho é o símbolo do pecado - logo, representa também o pecado da gula - o azul, como seu oposto, vem a simbolizar a temperança, o domínio da vontade sobre os instintos, a virtude de controlar o apetite, materializada pela escolha de um alimento menos doce, menos salgado, menos calórico, e, possivelmente, menos saboroso.

Foi observado que, na representação dos alimentos "saudáveis", o matiz azul estava principalmente associado a alimentos com teor reduzido de gordura. É a cor típica de produtos alimentícios que incorporam em sua concepção a ideia de regime alimentar, mas não parece se tratar apenas da escolha de uma cor insípida para representar esses alimentos, já que o campo semântico do azul abrange sentidos que de um modo ou de outro se aproximam de diferentes ideias envolvidas na ideologia do corpo perfeito. A esse respeito, já foi dito que o corpo magro seria um "graal", "objeto de uma verdadeira busca", um "[...] ideal quase inacessível, sempre perseguido, às vezes alcançado, raramente ou nunca possuído [...]" (FISCHLER, 2001 p. 354). Portanto, as embalagens azuis dos alimentos leves, aliados na busca por uma beleza idealizada, também resgatam sentidos tradicionais do azul, considerado a "cor do infinito, do longínquo, do sonho" (PASTOUREAU, 1993 p. 23). 


\section{CONSIDERAÇÕES FINAIS}

A despeito de ser uma cor estranha ao universo dos alimentos, o azul é muito presente no design de embalagens contemporâneo. Ele tem sido utilizado de modo recorrente para sinalizar aos consumidores um alimento mais nutritivo, menos calórico ou de algum outro modo visto como mais saudável, assumindo, a princípio, uma função indicativa no design. Contudo, ao representar uma ideia geral - nutrição e saúde - que remete a sistemas de significação mais amplos, a cor ultrapassa sua função de índice, traduzindo discursos que orientam as práticas alimentares contemporâneas e o consumo de alimentos.

A formação do signo azul=saudável pode ser explicada pela relação de oposição que se estabelece entre essa cor e as cores quentes características do universo dos alimentos, que representam o prazer da alimentação. Como contraponto ao apelo ao apetite, ao impulso, ao prazer dos sentidos, o azul, que tradicionalmente simboliza o pensamento, a razão, e é também historicamente relacionado à moralidade, representa a ideia de moderação, temperança e racionalidade que corresponde à opção pela alimentação leve.

No plano simbólico, o colorido do design aponta para tendências sociais mais amplas. A pesquisa identificou um processo de mudança em que os tradicionais vermelhos, laranjas e amarelos das embalagens de alimentos vêm sendo substituídos por cores frias, como o azul, atualmente usadas como signo de alimentação saudável - uma mudança do padrão cromático que reflete a ascendência do discurso científico vinculado à alimentação. Estes resultados demonstram que as cores das embalagens estabelecem vínculos com outros sistemas de significação, tanto quanto o caráter simbólico da cor nas embalagens de alimentos contemporâneas.

$\mathrm{O}$ azul das embalagens reflete conceitos promovidos pela sociedade nos dias de hoje, integrando um processo mais amplo de propagação de valores e símbolos. Ele se apresenta como tradução visual de uma ideia de saúde difundida na atualidade, que se confunde com um ideal de beleza baseado na magreza do corpo, um ideal aparentemente tão inatingível quanto o azul do infinito.

\section{REFERÊNCIAS}

BIRREN, Faber. Color psychology and color therapy. New York: McGraw-Hill Book Company, 1950.

CATHELAT, Bernard. Publicité et societé. Paris: Éditions Payot, 1968.

DANGER, Eric P. A cor na comunicação. (trad.) Ilza M. de Sá. Rio de Janeiro: Forum, 1973.

DUBOIS, Jean; GIACOMO, Mathée; GUESPIN, Louis. Dicionário de lingüística geral. (trad.) Izidoro Blikstein. 9a ed. São Paulo: Cultrix, 2004.

FAVRE, Jean-Paul; NOVEMBER, André. Color and und et communication. Zurich: $A B C$ Verlag, 1979.

FISCHLER, Claude. L'homnivore: le goût, la cuisine et le corps . Paris: Odile Jacob, 2001.

GOETHE, J. W. Doutrina das cores. (trad.) Marco Giannotti. São Paulo: Nova Alexandria, 1993. 
GROUPE $\mu$. Tratado del signo visual: para una retórica de la imagem. Madrid: Catedra, 1993.

HELLER, Eva. Psicología del color: cómo actúan los colores sobre los sentimientos y la razón. (trad.) Joaquín C Mielke. Barcelona: Gustavo Gili, 2004.

KANDINSKY, Wassily. Do espiritual na arte. (trad.) Álvaro Cabral e Antônio de P. Danesi. São Paulo: Matins Fontes, 2000.

PASTOUREAU, Michel. Bleu: histoire d'une couleur. S.I.: Éditions du Seuil, 2000.

-. Dicionário das cores do nosso tempo: simbólica e sociedade. (trad.) Maria José Figueiredo. Lisboa: Editorial Estampa, 1993.

PEIRCE, C. S. Semiótica. 2.ed. São Paulo: Perspectiva, 1995.

SAUSSURE, F. Curso de linguística geral. 27.ed. São Paulo : Cultrix, 2006. 